\title{
Aspectos do enfoque CTS no Ensino \\ Profissional Técnico de Nível Médio em feira de ciências
}

Ana Lúcia Lopes Corrêa

Mauro Sérgio Teixeira de Araújo

\begin{abstract}
Resumo
O objetivo deste trabalho é analisar e refletir sobre o ensino em uma instituição pública federal de educação profissional técnica de nível médio no que se refere à abordagem sobre CTS com base na percepção construída por alunos e professores durante uma feira de ciências. $O$ estudo é descritivo e de natureza quantitativa. A coleta de dados foi realizada pela aplicação de um questionário com 25 afirmativas para a escolha de apenas uma opção da escala Likert. Aqui são analisadas cinco delas. Os resultados iniciais revelam um cenário favorável para uma formação técnica cidadã com enfoque CTS.

Palavras-chave: Educação científica e tecnológica. Cidadania. Ciência, tecnologia e sociedade.
\end{abstract}

\section{Abstract}

The aim of this study is to analyze and reflect on the education in a federal public institution of middle level's professional technical education with regard to the approach on CTS based on perception built by students and professors during a science fair. The study is descriptive and quantitative in nature. Data collection was carried out by the application of a questionnaire with 25 statements for choosing only one Likert scale's option. Here are five of them analyzed. The initial results reveal a favorable scenario for a technical citizen training focusing CTS.

Key words: Science and technology education. Citizenship. Science, technology and society. 


\section{Introdução}

Vivemos em uma época de grandes mudanças científicas, tecnológicas e sociais. Em praticamente todas as áreas do conhecimento científico e tecnológico observamos avanços que, de algum modo, afetam a vida das pessoas. Da biotecnologia, com a manipulação genética dos alimentos, até a astrofísica, com a exploração espacial, esses avanços ressoam de modos diferentes ao revelarem efeitos positivos e negativos. Se por um lado os efeitos dos avanços e das atividades científicas e tecnológicas proporcionam melhoria na qualidade de vida das pessoas, como o controle de pragas e doenças, por outro ressoam ameaçadores à nossa vida e à de nosso planeta. A constatação dessa realidade leva-nos a acreditar que a sociedade está passando por transformações que a conduz olhar para a ciência e a tecnologia com mais cuidado. O poder e a verdade creditados à ciência mostram-se abalados nesse cenário repleto de novos riscos, perigos e incertezas.

Corroboramos com entendimentos de Ramsey (1993) que, há 20 anos, já acreditava que um processo educativo em ciências não poderia prescindir de discussões de questões relacionadas ao papel desempenhado pela ciência e tecnologia na sociedade e que deveríamos preparar nossos alunos para o exercício dos direitos e responsabilidades ligados à cidadania.

O desenvolvimento da Ciência e da Tecnologia (C\&T) tem produzido diversas transformações na sociedade do século XXI, com reflexos nos níveis econômico, político e social e envolvendo discussões e críticas. Na atualidade, a ideia central da educação com enfoque Ciência, Tecnologia e Sociedade (CTS) está orientada para o desenvolvimento de atividades com ênfase na tomada de decisões, sobretudo relacionadas com aspectos sociais impactados pela C\&T, implicando uma educação de valores éticos compromissados com a sociedade, chamada por Santos e Mortimer (2001, p.102) de "educação para a ação social responsável". Isto demanda a humanização da educação profissional e o combate ao tecnicismo ainda vigente. Moniz dos Santos (2005, p.145) afirma que a construção de uma cidadania cultural, crítica e ativa requer "ancorar os conhecimentos sobre ciência em perspectivas CTS eticamente orientadas, pois faz parte do sentido cívico analisar, compreender e reavaliar uma mudança que reclama ruptura [...] com o paradigma positivista". Assim, "importa reflectir (sic) sobre o estatuto e propósitos da tecnociência, o qual implica relações cidadania/tecnociência, poder democrático/ poder tecnocrático, economia/ambiente" (LÓPEZ-CEREZO, 2004, p.6).

Apresentamos nesse texto os primeiros resultados de uma pesquisa mais ampla desenvolvida em uma tese de doutorado que trata das relações CTS no ensino ofertado por uma instituição de ensino profissional técnico de nível médio na percepção de seus alunos e professores.

Consideramos como questão norteadora: o ensino oferecido na instituição federal pode ser considerado amparado no enfoque CTS? O objetivo é refletir sobre o ensino ofertado em uma 
instituição federal de educação profissional técnica de nível médio no que se refere à abordagem sobre Ciência, Tecnologia e Sociedade com base na percepção de alunos (com idades entre 15 e 19 anos) e professores orientadores abordados durante a realização de uma feira de ciências, em 2011, realizada em Belo Horizonte, MG.

\section{CTS, cidadania, educação científica e tecnológica}

Pode-se dizer que a ciência (conhecimento e capacidade para desenvolver e compreender representações do mundo) e a tecnologia (conhecimento e capacidade para fazer ou transformar alguma coisa) são campos de atividade cada vez mais interdependentes (PRAIA; CACHAPUZ, 2005). Basicamente a tríade Ciência, Tecnologia e Sociedade (CTS) estuda a inter-relação dos três segmentos e busca entender os aspectos sociais do desenvolvimento tecnocientífico tanto nos benefícios como nas consequências sociais e ambientais (PINHEIRO; SILVEIRA; BAZZO, 2009).

De acordo com Santos e Mortimer (2002), alfabetizar os cidadãos em ciência e tecnologia é hoje uma necessidade do mundo contemporâneo. Não se trata de mostrar as maravilhas da ciência, como a mídia já o faz, mas de disponibilizar as representações que permitam ao cidadão agir, tomar decisão e compreender o que está em jogo no discurso dos especialistas. Essa tem sido a principal proposição dos currículos com ênfase em Ciência, Tecnologia e Sociedade (CTS).

Santos e Schnetzler (1997) apresentam uma síntese do que seria desejável para um ensino com abordagem CTS. Na visão desses autores, a ciência deve ser considerada como uma busca de conhecimentos socialmente construídos que sofre influência tanto da tecnologia, que atua como facilitadora ou limitadora das pesquisas científicas, quanto da sociedade que pode nortear os rumos dessa ciência. A tecnologia sofre a influência tanto da ciência - a produção de novos conhecimentos científicos promove mudanças tecnológicas - como da sociedade que intervém por meio de pressões públicas e das necessidades sociais. Por fim, a sociedade deve ser vista como uma instituição humana e fortemente influenciada pela ciência e pela tecnologia visto que ambas alteram o modo de vida das pessoas. Desse modo, a compreensão da tríade C-T-S e de suas inter-relações é fundamental para o desenvolvimento do ensino pautado por abordagens CTS e devem ser discutidas no planejamento didático com os professores e na sala de aula com os alunos.

Constata-se preocupação no Brasil e em outros países sobre a educação instituída e quais os compromissos assumidos na formação dos alunos do ensino médio, principalmente relacionados ao controle social da C\&T. O objetivo central da abordagem CTS é promover a educação científica e tecnológica dos cidadãos, auxiliando o aluno a construir conhecimentos, habilidades e valores necessários para tomar decisões responsáveis sobre questões de C\&T na sociedade e atuar na solução de tais questões (YAGER, 1990; SOLOMON, 1993; SANTOS; 
SCHNETZLER, 1997; AIKENHEAD, 2001; SANTOS; MORTIMER, 2002; AULER, 2007; SANTOS, 2007;

AIKENHEAD, 2009; BAZZO, PINHEIRO; SILVEIRA, 2010; BERNARDO; VIANNA; SILVA, 2011).

Precisamos dispor, então, na medida necessária, "de conhecimentos em ciência e tecnologia, mas também sobre ciência e tecnologia" (MARTINS; PAIXÃO, 2011, p.144) e compor uma sociedade crítica e reflexiva, atenta às situações e dilemas decorrentes das relações entre C\&T e atividades sociais, econômicas e políticas, bem como aos riscos gerados pelas aplicações técnico-científicas.

Promover, em sala de aula, discussões no sentido de construir novas concepções sobre ciência, tecnologia e sociedade, poderá contribuir para minimizar visões inadequadas aos desafios impostos para a educação científica nos dias atuais.

\section{Material e métodos}

A abordagem deste estudo é descritiva e de natureza quantitativa. A coleta de dados foi realizada pela aplicação de um questionário com 25 afirmativas em que estudantes e professores escolheram apenas uma opção da escala Likert (nunca, raramente, às vezes, com frequência, sempre) durante uma feira de ciências, em que buscaram aplicar seus conhecimentos. Dezesseis afirmativas são mistas, ou seja, além de assinalar apenas uma opção, há um espaço em branco para que sejam fornecidos exemplos de situações vivenciadas sobre o tema abordado.

Neste texto, por restrição metodológica, focamos apenas a análise quantitativa de 5 afirmativas do instrumento de coleta de dados distribuído aos alunos e professores orientadores participantes da feira de ciências em Minas Gerais. As 5 afirmativas escolhidas representam, em nosso entendimento, a centralidade do enfoque CTS. A mostra contou com 132 trabalhos inscritos, 284 estudantes participantes e 132 professores orientadores.

A razão de essa feira ter sido escolhida para o universo da pesquisa se deveu à própria característica do evento: primeiramente, a feira é realizada há várias décadas na instituição e, segundo, ela reúne alunos (da educação profissional técnica de nível médio) interessados em apresentar trabalhos de pesquisa desenvolvidos em três modalidades: (1) Modelos Didáticos: trabalhos para ilustrar, aplicar, mostrar e revelar os princípios científicos de funcionamento de certos objetos, máquinas, mecanismos ou sistemas; (2) Processos e Produtos: iniciativa de construir algo com inventividade na função, forma, processo ou na proposição de soluções e materiais alternativos; e (3) Científico e Inovação Tecnológica: trabalhos voltados para a pesquisa em torno de problemas e situações do mundo científico, tecnológico ou do cotidiano, visando à sua maior compreensão e à indicação de possíveis soluções.

A aplicação dos questionários deu-se durante o evento e por via eletrônica, com o instrumento hospedado no servidor da instituição durante 45 dias. Após o recolhimento de todos 
os questionários respondidos por alunos e professores, procedeu-se à transcrição das respostas para planilhas do Excel. A análise qualitativa da parte discursiva das questões encontra-se em fase final de execução.

\section{Resultados e discussão}

As afirmativas selecionadas para a discussão neste texto (dentre as 25 originais) e suas ideias centrais são as de número 4 (controle social sobre as inovações científicas e tecnológicas), 5 (interações entre Ciência, Tecnologia e Sociedade), 7 (implicações sociais da Ciência), 8 (implicações sociais da Tecnologia) e a de número 16 (sujeito crítico).

A discussão e análise conjunta dessas e não de outras afirmativas do instrumento de coleta de dados se justificam pelo fato de as selecionadas contemplarem a essência de um ensino comprometido com a educação científica e tecnológica via CTS, ou seja, a de construir conhecimentos e desenvolver habilidades para tomadas de decisões responsáveis junto à sociedade (SANTOS, 2007).

A Tabela 1 se refere à compilação das 5 afirmativas selecionadas e em cada uma consta a frequência das respostas dos estudantes e dos professores orientadores em percentuais.

Tabela 1 - Afirmativas 4, 5, 7, 8 e 16 do questionário aplicado a 117 alunos e a 40 professores que apresentaram/orientaram trabalhos em uma feira científica em 2011, Belo Horizonte, MG.

\begin{tabular}{|c|c|c|c|c|c|c|c|c|}
\hline $\begin{array}{l}\frac{0}{2 \pi} \\
\stackrel{\Delta}{0} \\
\frac{0}{2}\end{array}$ & Afirmativa & $\begin{array}{l}\stackrel{0}{5} \\
\frac{3}{3} \\
\frac{1}{11} \\
4\end{array}$ &  & 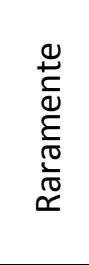 &  & 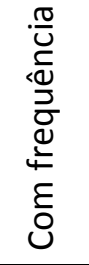 & 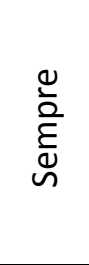 & 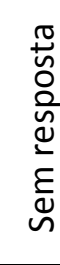 \\
\hline \multirow[t]{2}{*}{4} & \multirow{2}{*}{$\begin{array}{c}\text { Há discussão sobre a } \\
\text { importância e a defesa de } \\
\text { maior controle social sobre as } \\
\text { inovações científicas e } \\
\text { tecnológicas. Cite uma } \\
\text { situação. }\end{array}$} & A & $27 \%$ & $19 \%$ & $34 \%$ & $13 \%$ & $4 \%$ & $3 \%$ \\
\hline & & $P$ & $25 \%$ & $12 \%$ & $35 \%$ & $13 \%$ & $15 \%$ & $0 \%$ \\
\hline \multirow[t]{2}{*}{5} & \multirow{2}{*}{$\begin{array}{l}\text { Há discussão sobre as } \\
\text { interações entre Ciência, } \\
\text { Tecnologia e Sociedade com } \\
\text { os alunos. Cite uma situação. }\end{array}$} & A & $17 \%$ & $11 \%$ & $27 \%$ & $32 \%$ & $9 \%$ & $4 \%$ \\
\hline & & $P$ & $10 \%$ & $2 \%$ & $23 \%$ & $30 \%$ & $35 \%$ & $0 \%$ \\
\hline \multirow[t]{2}{*}{7} & \multirow{2}{*}{$\begin{array}{l}\text { Há abordagem sobre as } \\
\text { implicações sociais da Ciência } \\
\text { (conseqüências e impactos) } \\
\text { nas disciplinas do curso. Cite } \\
\text { uma situação. }\end{array}$} & A & $17 \%$ & $15 \%$ & $35 \%$ & 19\% & $10 \%$ & $4 \%$ \\
\hline & & $P$ & $12 \%$ & $5 \%$ & $32 \%$ & $28 \%$ & $23 \%$ & $0 \%$ \\
\hline
\end{tabular}




\begin{tabular}{|c|c|c|c|c|c|c|c|c|}
\hline \multirow[t]{2}{*}{8} & \multirow{2}{*}{$\begin{array}{l}\text { Há abordagem sobre as } \\
\text { implicações sociais da } \\
\text { Tecnologia (conseqüências e } \\
\text { impactos) nas disciplinas do } \\
\text { curso. Cite uma situação. }\end{array}$} & A & $18 \%$ & $11 \%$ & $31 \%$ & $19 \%$ & $15 \%$ & $6 \%$ \\
\hline & & $P$ & $10 \%$ & $5 \%$ & $17 \%$ & $35 \%$ & $28 \%$ & $5 \%$ \\
\hline \multirow[t]{2}{*}{16} & \multirow{2}{*}{$\begin{array}{l}\text { Existe contribuição para a } \\
\text { formação do aluno de modo a } \\
\text { torná-lo um sujeito crítico, } \\
\text { consciente dos seus direitos e } \\
\text { deveres individuais e sociais. }\end{array}$} & A & $1 \%$ & $3 \%$ & $15 \%$ & $32 \%$ & $46 \%$ & $3 \%$ \\
\hline & & $P$ & $0 \%$ & $2 \%$ & $13 \%$ & $25 \%$ & $60 \%$ & $0 \%$ \\
\hline
\end{tabular}

A análise das informações contidas na Tabela 1 possibilita que sejam realizadas considerações interessantes.

Quando perguntados se em seus cursos é discutida a importância e a defesa de maior controle social sobre as inovações científicas e tecnológicas (afirmativa 4), 46\% dos alunos responderam nunca e raramente, e $34 \%$ às vezes. Já $37 \%$ dos professores responderam nunca e raramente, e $35 \%$ às vezes. No quesito com frequência ambos os grupos responderam $13 \%$, mas apenas $4 \%$ dos estudantes afirmaram sempre contra $15 \%$ dos professores. A maior divergência entre as respostas de estudantes e professores está na opção sempre (Gráfico 1).

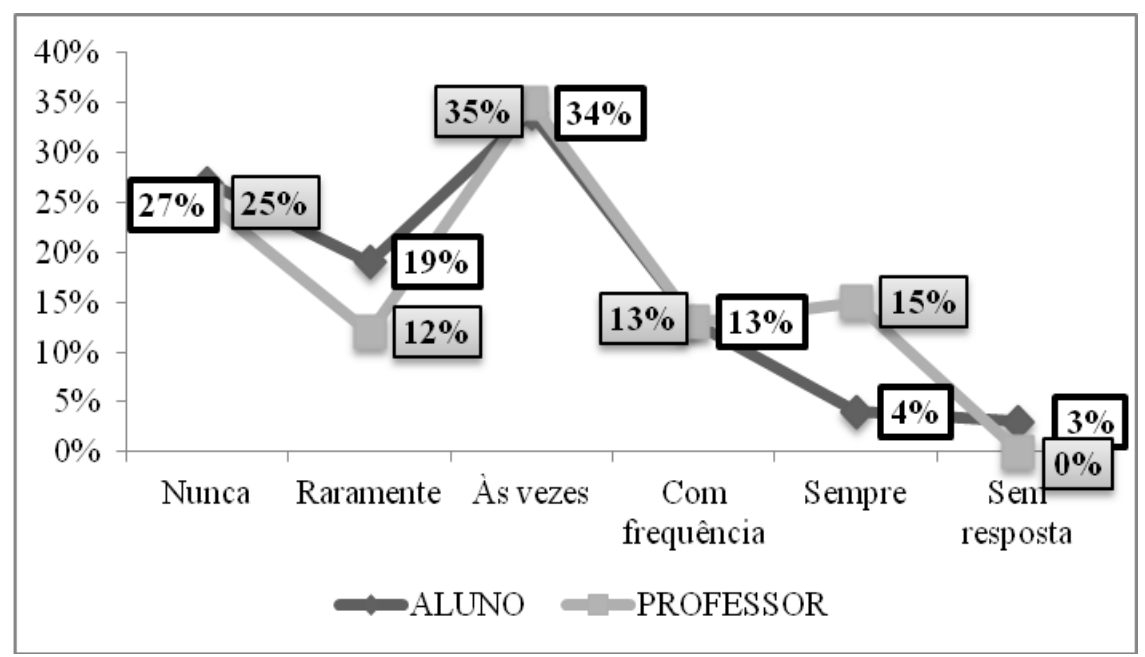

Gráfico 1 - Afirmativa 4 - Há discussão sobre a importância e a defesa de maior controle social sobre as inovações científicas e tecnológicas

O Gráfico 1 mostra que de um lado, em nível de prática pedagógica, as respostas dos professores apontam para uma ruptura com a concepção tradicional que predomina na escola e tentam promover uma nova forma de entender a produção do saber. Tal postura vai além do academicismo e cientificismo ao se preocuparem com os problemas sociais relacionados com o contexto cientifico-tecnológico. Esse tipo de prática objetiva desmitificar o espírito de neutralidade da ciência e da tecnologia ao ressaltar sua responsabilidade política. A discussão da importância e da defesa de maior controle social sobre as inovações científicas e tecnológicas é entendida como a educação de alunos e cidadãos orientada para uma reflexão crítica sobre uma 
"educação para a ação social responsável" (SANTOS; MORTIMER, 2001, p.102), a qual vai além da memorização de sistemas classificatórios, definições e resolução de exercícios (SANTOS, 2009).

Do outro lado, os estudantes de cursos técnicos que, em sua maioria, fazem uso de tecnologias em seus cursos e na vida pessoal, parecem não perceber ou não entender os objetivos das ações pedagógicas de seus professores. Era de se esperar um significativo interesse deles por compreender o funcionamento da tecnociência, no sentido de alcançar, além do acesso às informações sobre o desenvolvimento cientifico-tecnológico, condições de avaliar e participar de decisões que venham a atingir o meio onde vivem (Gráfico 1).

Na afirmativa 5, 28\% dos estudantes responderam nunca e raramente e $27 \%$ às vezes para as discussões acerca das interações C, T e S. Houve grande diferença nas respostas dos professores para nunca e raramente $(12 \%)$, mas equilibrou-se em às vezes $(23 \%)$. Nas respostas dos estudantes para com frequência e sempre também houve disparidade nas respostas em relação às dos professores ( $41 \%$ e $65 \%$, respectivamente). Novamente a maior discrepância entre as respostas de alunos e professores situa-se na opção sempre (Gráfico 2).

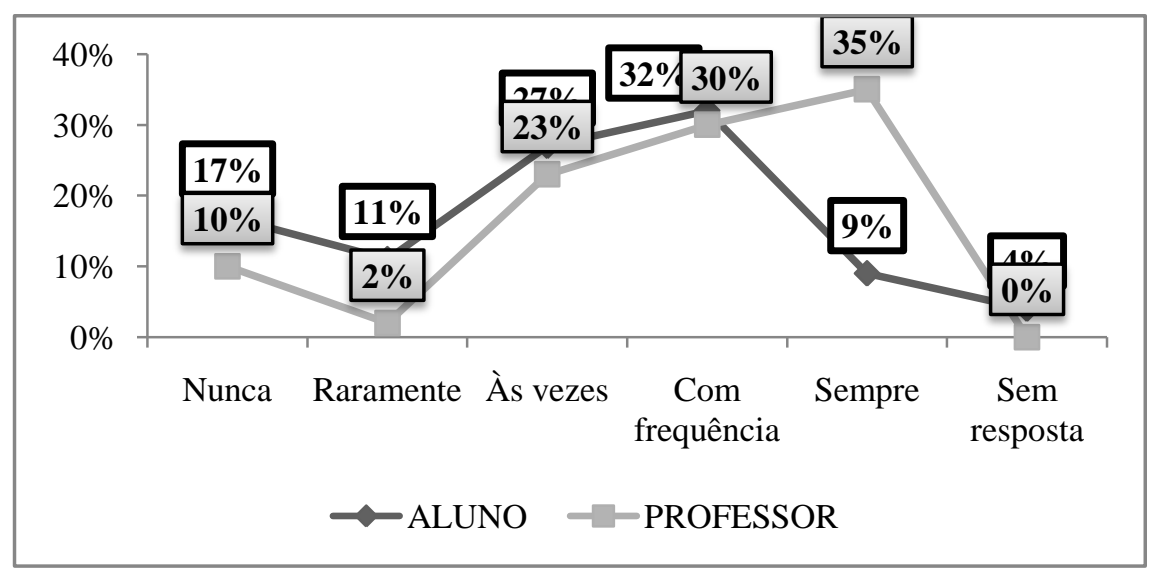

Gráfico 2 - Afirmativa 5 - Há discussão sobre as interações entre Ciência, Tecnologia e Sociedade com os alunos

Conforme o Gráfico 2, os professores se preocupam em propiciar aos alunos o desenvolvimento de capacidades suficientes para que eles possam entender e seguir debates científicos e envolver-se nas questões que a tecnologia coloca, quer como indivíduos, quer para a sociedade como um todo. Essa orientação para o ensino das ciências corresponde à ideia de ensino para a literacia científica ligada ao exercício de uma cidadania responsável, que inclui "conhecimento substantivo, processual, epistemológico, pensamento crítico, capacidade de exposição de ideias, de elaboração de argumentos, de análise e de síntese, como também a explicitação de atitudes inerentes ao trabalho em ciência" (MARTINS; PAIXÃO, 2011, p.148). Em contrapartida, índices semelhantes nas opções às vezes e com frequência para professores e alunos apontam para um ensino que valoriza a contextualização e fomenta um conhecimento que integra capacidades de pensamento, de atitudes e valores para compreender o mundo em sua globalidade e complexidade. 
As respostas dos estudantes às afirmativas 4 e 5 se contradizem: a não ocorrência de discussões sobre a defesa de maior controle social sobre as inovações científicas e tecnológicas não condiz com as frequentes discussões acerca das interações C, T e S. Será que esses estudantes não sabem o que significa 'controle social'? Ou não entenderam o que estava sendo perguntado? Isso demanda analisar qualitativamente as respostas dadas a essa afirmativa.

No entendimento da maioria dos estudantes quanto à afirmativa 7 , as implicações sociais da ciência não são discutidas nas disciplinas de seus cursos. Assim, 32\% responderam nunca e raramente. Às vezes foi a resposta de $35 \%$ dos alunos. Dos professores, $17 \%$ responderam nunca e raramente e $32 \%$ às vezes. Houve disparidade nas respostas de com frequência e sempre $(29 \%$ dos alunos e $51 \%$ dos professores) (Gráfico 3 ).

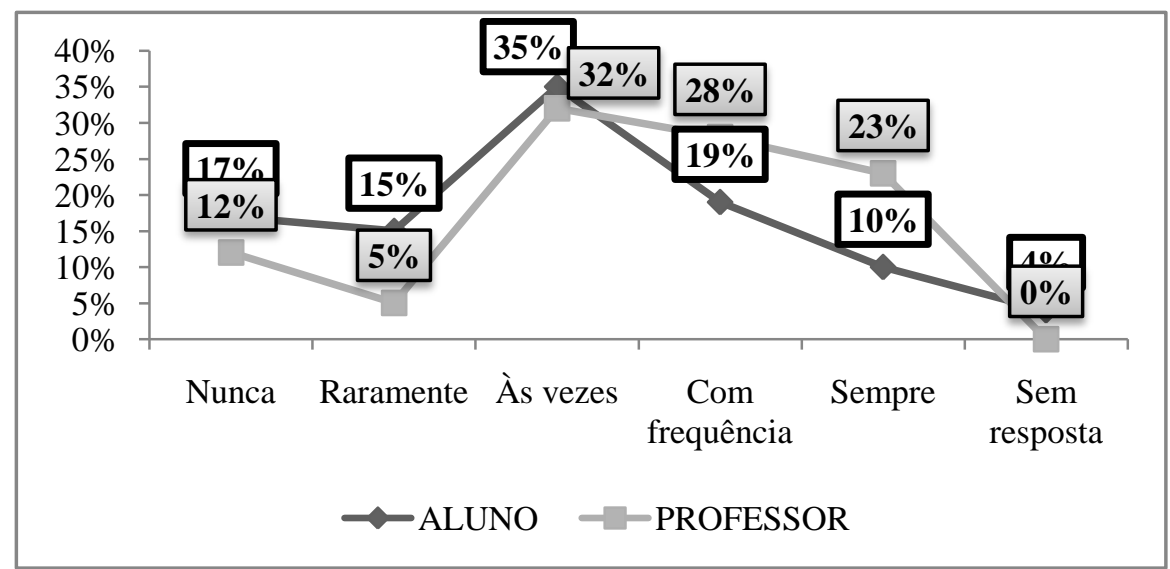

Gráfico 3 - Afirmativa 7 - Há abordagem sobre as implicações sociais da Ciência (consequências e impactos) nas disciplinas

No tocante aos dados constantes do Gráfico 3, compartilhamos da opinião de Norris e Phillips (2003) por entendermos que para fazer uso social da ciência o cidadão precisa saber ler e interpretar as informações científicas difundidas na mídia escrita. Isto significa saber usar estratégias para extrair informações e fazer inferências, compreendendo que um texto científico pode expressar diferentes ideias, identificar o papel do argumento científico na construção das teorias, reconhecer as possibilidades do texto ser interpretado e reinterpretado, além de compreender as limitações teóricas impostas, entendendo que sua interpretação implica a não aceitação de certos argumentos.

Nessa perspectiva, pode-se dizer que a apropriação de conceitos das ciências físicas e naturais têm se tornado um objetivo formativo imprescindível para auxiliar a atuação dos indivíduos em uma sociedade do conhecimento, imersa em informações quantitativas e marcadas pelos produtos de ciência e da tecnologia. No cotidiano, todos são confrontados a ler e interpretar uma série de informações: bulas de remédios, características de produtos alimentares, melhores alternativas na aquisição de algum equipamento, além de decidir ou tomar posição em questões públicas em favor de um grupo ou de uma comunidade. Entendemos que os usos da ciência como um recurso a ser empregado em situações da vida, do trabalho e para entendimento 
do mundo requer, em contra partida, desenvolver nos alunos uma compreensão sobre a natureza da ciência. Implica discutir seus limites, seu caráter provisório e suas implicações sociais. Nos currículos de ciências com enfoque CTS faz-se necessária a abordagem de questões relativas à ciência de natureza filosófica, sociológica, histórica, política, econômica e humanística, como sugere Rosenthal (1989). Assim, no processo de tomada de decisão racional e esclarecida, é crucial o uso de conhecimento conceitual relevante, bem como de capacidades de pensamento crítico, nomeadamente para pesar, comparar e avaliar as vantagens e desvantagens de opções disponíveis.

Mais uma vez defendemos que a orientação CTS e o pensamento crítico constituem-se elementos fundamentais em currículos de ciências e da matemática em uma perspectiva de literacia, visando à formação de cidadãos capazes de pensar e agir criticamente sobre questões sociais de âmbito científico-tecnológico.

Retomando-se o questionário, nos resultados sobre se implicações sociais da tecnologia têm sido abordadas em sala de aula (afirmativa 8), 29\% dos alunos responderam nunca e raramente e $31 \%$ responderam às vezes. Quanto aos professores, $15 \%$ responderam nunca e raramente e $17 \%$ responderam às vezes. Com frequência e sempre foram respostas de $34 \%$ dos alunos e de $63 \%$ dos professores (Gráfico 4).

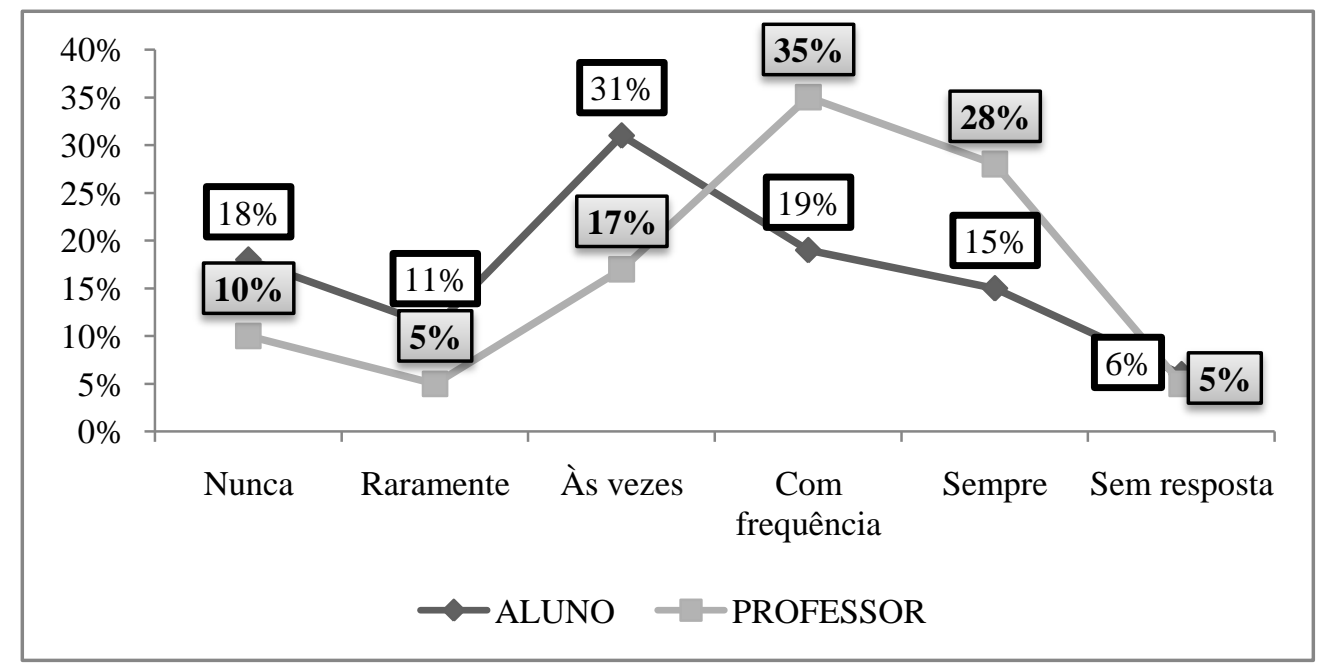

Gráfico 4-Afirmativa 8 - Há abordagem sobre as implicações sociais da Tecnologia (consequências e impactos) em sua disciplina

Para Santos e Mortimer (2002), nas disciplinas ofertadas nos cursos técnicos a abordagem sobre a tecnologia ainda é reduzida apenas ao seu aspecto técnico. Neste caso (Gráfico 4), os resultados divergem do entendimento desses autores, pois demonstram que os professores acreditam criar condições para abordagens sobre as implicações sociais da tecnologia em suas disciplinas, mas existe um evidente descompasso entre a prática pedagógica e a percepção dos alunos frente às intenções de seus professores. 
Isso confirma nossa percepção de que, de maneira geral, nos últimos tempos estar sendo defendida uma educação em ciências, tecnologia e matemática em uma perspectiva de literacia científica, tecnológica conforme palavras de (TENREIRO-VIEIRA; VIEIRA, 2011, p. 420) ${ }^{1}$.

[...] por oposição a uma lógica de mera instrução, que promova o desenvolvimento pessoal dos alunos e lhes permita pensar por si próprios, enfrentar a vida e participar ativa e adequadamente no planejamento $e$ resolução de solução de problemas e necessidades sociais, de forma a viabilizar o desenvolvimento de modos de vida mais justos e democráticos.

Rutherford e Ahlgren (1995), Halpern (1996) e Holbrook et al. (2000) argumentam que a educação em ciências, tecnologia e matemática deve ajudar todos os alunos a desenvolverem os conhecimento, as atitudes e as capacidades de pensamento requeridas para a promoção de um desenvolvimento sustentável em nível local, nacional e internacional para que todos possam ter vidas produtiva e gozar de qualidade de vida. Em síntese, a meta da orientação CTS no contexto da educação em Ciências tem buscado promover a alfabetização (literacia) científica e tecnológica dos cidadãos para propósitos pessoais e sociais (MEMBIELA, 1997; ACEVEDO-DÍAZ et al., 2002a,b).

A afirmativa 16 apresenta a percepção dos alunos e professores quanto à formação de alunos como cidadãos críticos. Esse resultado é bem diferente dos anteriores. Quando perguntados se "a formação adquirida na instituição contribui para torná-lo um sujeito crítico, consciente de seus direitos e deveres individuais e sociais", apenas $4 \%$ dos alunos responderam nunca e raramente e $15 \%$ responderam às vezes enquanto $78 \%$ responderam com frequência $e$ sempre. Os professores responderam $2 \%$ para nunca e raramente e $13 \%$ responderam às vezes enquanto $85 \%$ responderam com frequência e sempre. Esses resultados apontam para um ensino amparado no enfoque CTS do ponto de vista das intenções dos professores. Entretanto, uma via de mão única parece existir entre a perspectiva do processo de ensino e aprendizagem tanto na parte conceitual quanto na procedimental. Os professores oportunizam, promovem e mobilizam meios para abordagem CTS e para a formação de sujeitos críticos, mas os índices das afirmativas anteriores respondidas pelos estudantes não corroboram o percentual obtido na afirmativa 16 .

Contudo, pode-se questionar: sabem os alunos o que significa ser um sujeito crítico? Obter essa resposta demanda investigar, comparar e confrontar as respostas em outras

\footnotetext{
${ }^{1}$ Tenreiro-Vieira,Celina; Vieira, Rui Marques. Educação em ciências e em matemática numa perspectiva de literacia: desenvolvimento de materiais didático com orientação CTS / pensamento crítico (PC). In: SANTOS, Wilson Luiz Pereira dos; AULER, Décio. CTS e educação científica: desafios, tendências e resultados de pesquisas. Brasília: Editora UNB, 2011, cap.14, p.417-437.
} 
afirmativas coletadas para identificarmos o entendimento desses sujeitos no que diz respeito a 'ser um sujeito crítico, consciente de seus direitos e deveres individuais e sociais' (Gráfico 5).



Gráfico 5 - Afirmativa 16 - Existe contribuição para a formação do aluno de modo a torná-lo um sujeito crítico, consciente dos seus direitos e deveres individuais e sociais

Com relação ao Gráfico 5, podemos questionar, também, como um professor pode ensinar o aluno a ser crítico. Em seu livro 'A filosofia do ensino', Passmore (1980, p.166) coloca a pergunta "o que é ensinar uma criança a ser crítica e como podemos afirmar que o fizemos com êxito? Seria uma questão de transmitir fatos, inculcar hábitos, treinar habilidades, desenvolver capacidades, formar o caráter, ou algo diferente de tudo isso?" Ao analisar cada uma dessas possibilidades, o autor afirma que ensinar um estudante a ser crítico não resulta da simples transmissão de fatos relacionados à crítica, como Paulo Freire também ressaltava. Para Passmore (1980), relatar o espírito crítico dos cientistas de pouco servirá para o aluno desenvolver espírito crítico pessoal, pois o espírito crítico está mais relacionado a um traço de caráter e este, por sua vez, está implicado com a formação recebida.

Entretanto, para pensar criticamente é necessário ter estimulado o ato reflexivo, o que significa desenvolver a capacidade de observação, reflexão, análise, crítica, autonomia no pensar e nas ideias, significa ampliar os horizontes, tornar-se agente ativo nas transformações da sociedade, buscar interagir com a realidade (SORDI; BAGNATO, 1998).

Ao confrontar os alunos com problemas atuais de âmbito social, ético e político, a partir de uma perspectiva da Ciência e da Tecnologia, o pensamento crítico em CTS cria oportunidades para os alunos refletirem, formularem opiniões/juízos de valor, apresentarem soluções e tomarem decisões sobre acontecimentos e/ou problemas do mundo real (MAGALHÃES; TENREIRO-VIEIRA, 2006).

Pode-se dizer, então, que a orientação CTS, ao aproximar o ensino das Ciências das necessidades dos alunos como membros de uma sociedade cada vez mais desenvolvida científica 
e tecnologicamente (VILCHES, 2002), ao contribuir para melhorar a atitude e o interesse dos alunos em relação à Ciência e à sua aprendizagem, ao permitir aprender mais Ciência e saber mais sobre a Ciência, ao mostrar uma imagem mais completa e contextualizada da mesma (SOLOMON, 1995; MEMBIELA, 1995) e ao preparar os alunos para o exercício de uma cidadania responsável e para uma melhor integração no mundo do trabalho (ACEVEDO-DíAZ, 2001), apresenta-se como uma aposta com futuro e uma via promissora em termos de maior motivação dos alunos e da sua melhor preparação para darem uma resposta mais adequada aos problemas científicotecnológicos do mundo contemporâneo (CACHAPUZ et al., 2000).

\section{Considerações finais}

Pelos dados aqui apresentados, exceto pela afirmativa 16, a percepção dos alunos diverge bastante da intenção dos professores de construir conhecimentos, desenvolver habilidades e valores de juízo éticos e morais para tomadas de decisões responsáveis junto à sociedade.

Com base no que foi exposto, podemos nos perguntar: que tipo de atividade poderia contribuir para a formação de cidadãos críticos, autônomos e participativos? Tudo indica que desenvolver o espírito crítico envolve incentivar os alunos a buscar o valor subjacente às práticas em que estão envolvidos e não simplesmente ao desempenho, incentivando disponibilidade e criatividade para colocar em xeque regras, valores e práticas estabelecidos.

Destacamos aspectos do controle social sobre ciência e tecnologia que devem ser considerados, dentre sugestões de Santos e Mortimer (2001): (1) experiências de outros países devem ser avaliadas, já que muitas vezes alguns modelos são transferidos para a realidade brasileira sem considerar as necessidades de cada contexto e os problemas existentes; (2) a formação de professores deve ser modificada e/ou aprimorada, pois são poucas as instituições no Brasil com alguma linha de pesquisa voltada para o enfoque CTS; e (3) a formação disciplinar também é um problema que não condiz com o enfoque CTS, pois nem docentes nem estudantes brasileiros foram ou estão sendo formados em uma perspectiva interdisciplinar.

Os resultados iniciais de nossa investigação sobre o ensino em uma instituição federal no que diz respeito ao enfoque CTS revelam um cenário onde tal abordagem apresenta-se como uma postura que parece ser assumida pelos educadores com a intenção de favorecer nos estudantes a construção de atitudes, valores e normas de conduta em relação aos temas abordados nas afirmativas analisadas. Esta postura visa a uma formação que abre caminhos para o exercício da cidadania e prepare os alunos para tomadas de decisões que se fundem no bem-estar da maioria. Em contrapartida, os estudantes parecem não assimilar ou reconhecer as intenções de seus professores. Resultados semelhantes foram obtidos em outras investigações (SOLBES; VILCHES, 1988; AGUILAR, 2001; SOLBES; VILCHES, 2004) realizadas com estudantes espanhóis de faixa etária semelhante: a grande maioria não conhece os problemas que afetam ou que poderão 
afetar a humanidade no futuro, suas causas ou as soluções possíveis e o que cada um pode fazer para reverter o quadro.

O ensino das disciplinas científicas precisa passar por transformações e questionamentos que tentem responder às modificações sociais, à crescente diversificação cultural da sociedade, ao impacto tecnológico, às transformações do mercado de trabalho e às transformações da ciência. A produção e a apresentação de informações científicas envolvem julgamentos de valor e, por esse motivo, entre as questões que se colocam hoje para o tratamento das questões relativas a CTS estão aquelas que dizem respeito diretamente aos conceitos implicados, aos procedimentos, ao desenvolvimento de atitudes e valores e à preparação para a tomada de decisões. Fica clara a importância dos conteúdos referentes a normas, valores e atitudes quando do tratamento das questões relativas à CTS.

Desse modo, entendemos que ainda se faz necessário elaborar propostas e ações que possibilitem mobilizar e discutir com professores novas maneiras de apresentar os conteúdos científicos a partir, por exemplo, de abordagem temática (DELIZOICOV; ANGOTTI; PERNAMBUCO, 2003) e de discussões de controvérsias sociocientíficas sobre as interações CTS (REIS; GALVÃO, 2009). Essas estratégias metodológicas favorecem a prática da participação entre estudantes e auxiliam a concretizar as práticas didático-pedagógicas dos professores (VIEIRA; BAZZO, 2007; SANTOS; MORTIMER, 2009; BERNARDO; VIANNA; SILVA, 2011).

A educação em Ciências deve permitir, então, a todos os indivíduos, um melhor conhecimento da Ciência e das suas inter-relações com a Tecnologia e a Sociedade, conhecimento este que deve estar imbuído de pensamento crítico (VIEIRA; MARTINS, 2004).

A integração da orientação CTS no ensino das Ciências fomenta uma educação de perfil mais humanista, mais global e menos fragmentada (MARTINS, 2002a,b). Ao advogar uma ênfase nas relações entre a Ciência, a Tecnologia e a Sociedade, essa orientação revela uma imagem mais completa e mais real da Ciência e uma atitude mais positiva face à Ciência e à sua aprendizagem (VILCHES, 2002).

Percebemos que a literatura fornece experiências acerca de diferentes projetos desenvolvidos e conscientiza cada vez mais sobre as potencialidades do enfoque CTS para a melhoria da educação científica e tecnológica, sobretudo no que diz respeito às possibilidades de contextualização social da ciência e dos conteúdos que a perspectiva CTS oferece, como afirmam Bernardo, Vianna e Silva (2011). O enfoque CTS contribui no sentido de auxiliar o professor a aplicar estratégias que possibilitem ao aluno desenvolver seu lado crítico e reflexivo, ao analisar situações e tomar decisões que envolvam seu cotidiano. 


\section{Referências}

Acevedo-Díaz, J. A.; Vázquez, A.; Manassero, M. A.; Acevedo, P. Actitudes y creencias CTS de los alumnos: su evaluación con el Cuestionario de Opiniones sobre Ciencia, Tecnología y Sociedad. Revista Iberoamericana de Ciencia, Tecnología, Sociedad e Innovación, n.2, 2002a. Disponível em: http://www.campusoei.org/revistactsi/numero2/varios1.htm. Acesso em: 13 jan. 2013.

Acevedo-Díaz, J. A.; Vázquez, A.; Manassero, M. A.; Acevedo, P. Persistencia de las actitudes y creencias CTS en la profesión docente. Revista Electrónica de Enseñanza de las Ciencias, v.1, n.1 p.1-27, 2002b. Disponível em: http://www.saum.uvigo.es/reec. Acesso em: 13 jan. 2013.

Acevedo-Díaz, José A. Educación tecnológica desde una perspectiva CTS. Una breve revisión del tema. Sala de Lecturas CTS+I de la OEI, 2001. Disponível em:

www.campusoei.org/salactsi/acevedo5.htm. Acesso em: 13 jan. 2013.

Aguilar, T. Aprendizaje de las ciencias y ejercicio de la ciudadanía. In: MEMBIELA, E. (ed.), Enseñanza de las ciencias desde la perspectiva ciencia-tecnología-sociedad: formación científica para la ciudadanía, Madrid: Narcea, 2001, p.77-89.

Aikenhead, Glen (ed.). STS Education: international perspectives on reform [1994]. $8^{\text {th }}$ reprint. New York: Teachers College Press, 2001, chap.5, p.47-59.

Aikenhead, Glen. Educação Científica para todos. Mangualde e Ramada, Portugal: Pedago, 2009.

Auler, Décio. Articulação entre pressupostos do educador Paulo Freire e do movimento CTS: novos caminhos para a educação em ciências. Contexto e Educação, v. 22, n. 77, p. 167-188, jan./jun.2007.

Bazzo, Walter Antonio; Pinheiro, Nilcéia Aparecida Maciel; Silveira, Rosemari Monteiro Castilho Foggiatto. A perspectiva social do desenvolvimento científico e tecnológico. Revista de Ensino de Engenharia, v.29, n.1, p. 3010, 2010.

Bernardo, José Roberto da Rocha, Vianna, Deise Miranda; Silva, Vitor Hugo Duarte da. A construção de propostas de ensino em Ciência-Tecnologia-Sociedade (CTS) para abordagem de temas sociocientíficos. In: SANTOS, Wilson Luiz Pereira dos; AULER, Décio (Org.). CTS e educação científica: desafios, tendências e resultados de pesquisas. Brasília: Editora Universidade de Brasília, 2011, cap.12, p.373-293.

Cachapuz, António; Praia, João; Jorge, Manuela. Reflexão em torno de perspectivas de ensino das ciências: contributos para uma nova Orientação Curricular - Ensino por Pesquisa. Revista de Educação, v. 9, n.1, p. 69-78, 2000.

Delizoicov, Demétrio, Angotti, José André; Pernambuco, Marta Maria, Ensino de ciências: fundamentos e métodos. São Paulo: Cortez, 2003. 
Halpern, Dianne. Thought and knowledge: an introduction to critical thinking. 3 ed. Mahwah, NJ: Lawrence Erlbaum Associates, 1996.

Holbrook, Jack; MUKHERJEE, Amitabha; Varma, Vijaya. Scientific and technological literacy for all. UNESCO-ICASO-CSEC, Delhi Workshop. Delhi: Centre for Science Education and Communication, University of Delhi, 2000. 140p.

López-Cerezo, José Antônio. Ciência, Tecnologia e sociedade: o estado da arte na Europa e nos Estados Unidos. In: SANTOS, Lucy Woellner et al. (Org.) Ciência, tecnologia e sociedade: o desafio da interação. Londrina: IAPAR, 2004, p.11-44.

Magalhães, Sandra Isabel Rodrigues; Tenreiro-Vieira, Celina. Educação em Ciências para uma articulação Ciência, Tecnologia, Sociedade e Pensamento crítico: um programa de formação de professores. Revista Portuguesa de Educação, v.19, n.2, p. 85-110, 2006.

Martins, Isabel P. Problemas e perspectivas sobre a integração CTS no sistema educativo português. Revista Electrónica de Enseñanza de las Ciencias, v 1, n.1, 2002a. Disponível em: http://www.saum.uvigo.es/reec. Acesso em: 18 jan. 2013.

Martins, Isabel P. Educação e Educação em Ciências. Aveiro: Universidade de Aveiro, 2002b. Martins, Isabel P.; Paixão, Maria de Fátima. Perspectivas atuais Ciência-Tecnologia-Sociedade no ensino e na investigação em educação em ciência. In: SANTOS, Wilson Luiz Pereira dos; AULER, Décio (Org.). CTS e educação científica: desafios, tendências e resultados de pesquisas. Brasília: Editora UNB, 2011, cap.5, p.135-160.

Membiela, Pedro. CTS en la enseñanza-aprendizaje de las Ciencias Experimentales. Alambique. Didáctica de las Ciencias Experimentales, n.3, p.7-11, 1995.

Membiela, Pedro. Una revisión del movimiento educativo ciencia-tecnología-sociedad. Enseñanza de las Ciencias, v.15, n.1, p. 51-57, 1997.

Moniz dos Santos, Maria Eduarda Vaz. Cidadania, conhecimento, ciência e educação CTS. Rumo a "novas" dimensões epistemológicas. Revista Iberoamericana de Ciencia, Tecnología y Sociedad CTS, v.2, n.6, p.137-157, diciembre, 2005.

Norris, Stephen P.; Phillips, Linda M. How literacy in its fundamental sense is central to scientific literacy. Science Education, v. 87, n. 2, p. 224-240, 2003.

Passmore, John. The philosophy of teaching. London: Duckworth, 1980.

Pinheiro, Nilcéia Aparecida Maciel; Silveira, Rosemari Monteiro Castilho Foggiatto; Bazzo, Walter Antonio. O contexto científico-tecnológico e social acerca de uma abordagem crítico-reflexiva: perspectiva e enfoque. Revista Iberoamericana de Educación, v.49, n.1, 2009.

Praia, João; Cachapuz, António. Ciência-Tecnologia-Sociedade: um compromisso ético. Revista Iberoamericana de Ciencia, Tecnología Y Sociedad, Madrid, v.2, n.6, p.173-194, 2005. 
Reis, Pedro; Galvão, Cecília. Teaching controversial socio-scientific issues in Biology and Geology classes: a case study. Journal of Science Education, Washington, v.13, n.1, p.1-24, 2009.

Ramsey, J. The Science education reform movement: Implications for social responsibility. Science Education, v.77, n.2, p.235-258, 1993.

Rosenthal, Dorothy. B. Two approaches to science-technology-society (S-T-S) education. Science Education, v.73, n.5, p.581-589, 1989.

Rutherford, James; Ahlgren, Andrew. Ciência para todos. Trad. Catarina Martins. Lisboa: Gradiva, 1995.

Santos, Wildson Luiz Pereira dos. Educação científica e tecnológica: um compromisso de educadores e cientistas para o desenvolvimento da ciência e tecnologia no Brasil. Revista Virtual de Gestão de Iniciativas Sociais, n. especial, março 2009.

Santos, Wildson Luiz Pereira dos. Educação científica na perspectiva de letramento como prática social: funções, princípios e desafios. Revista Brasileira de Educação, v.12, n.36, p.474-550, set./dez. 2007.

Santos, Wildson Luiz Pereira dos; Mortimer, Eduardo Fleury. Abordagem de aspectos sociocientíficos em aulas de Ciências: possibilidades e limitações. Investigações em Ensino de Ciências, v.14, n.2, p.191-218, 2009.

Santos, Wildson Luiz Pereira dos; Mortimer, Eduardo Fleury. Tomada de decisão para ação social responsável no ensino de ciências. Ciência \& Educação, v.7, n.1, p.95-111, 2001.

Santos, Wildson Luiz Pereira dos; Mortimer, Eduardo Fleury. Uma análise dos pressupostos teóricos da abordagem C-T-S (Ciência - Tecnologia - Sociedade) no contexto da educação brasileira. Ensaio, UFMG Belo Horizonte, v. 2, n. 2, p.133-162, dezembro, 2002.

Santos, Wildson Luiz Pereira dos; Schnetzler, R. P. Educação química: compromisso com a cidadania. ljuí: Editora Unijuí, 1997.

Solbes, Jordi; Vilches, Amparo. Las interacciones CTS en los nuevos textos de la enseñanza secundaria. In: Banet, E.; de Pro, A. (Coord.). Investigación e innovación en la enseñanza de las ciencias. Murcia: Universidad de Murcia, 1998, p.142-148.

Solbes, Jordi; Vilches, Amparo. Papel de las relaciones entre ciencia, tecnología, sociedad y ambiente en la formación ciudadana. Enseñanza de las Ciencias, v. 22, n. 3, p.337-347, 2004.

Solomon, J. Methods of teaching STS. In: Mccormick, R., Murphy, P.; Harrison, M. (eds.). Teaching and learning technology. Workingham: Addison-Wesley Publishing Company \& The Open University, 1993, p.243-250.

Solomon, Joan. El estudio de la Tecnología en la educación. Alambique. Didáctica de las Ciencias Experimentales, n.3, p.13-18, 1995.

R. B. E. C. T., vol 6, núm. 3, set-dez.2013 ISSN - 1982-873X 
Sordi, M. R. L. de; Bagnato, M. H. S. Subsídios para uma formação profissional crítico-reflexiva na área de saúde: o desafio da virada do século. Revista Latino-americana de Enfermagem, Ribeirão Preto, v.6, n.2, p.83-88, abr.1998.

Stiefel, Berta M. La naturaleza de la Ciencia en los enfoques CTS. Alambique Didáctica de las Ciencias Experimentales, n.3, p.19-29, 1995.

Tenreiro-Vieira,Celina; Vieira, Rui Marques. Educação em ciências e em matemática numa perspectiva de literacia: desenvolvimento de materiais didático com orientação CTS / pensamento crítico (PC). In: SANTOS, Wilson Luiz Pereira dos; AULER, Décio. CTS e educação científica: desafios, tendências e resultados de pesquisas. Brasília: Editora UNB, 2011, cap.14, p.417-437. Vieira, Kátia Regina Cunha Flor; Bazzo, Walter Antonio. Discussões acerca do aquecimento global: uma proposta CTS para abordar esse tema controverso em sala de aula. Revista Ciência e Ensino, Campinas, v.1, n. especial, 2007. 12p.

Vieira, Rui M.; Martins, Isabel P. Impacto de um programa de formação com orientação CTS/PC nas concepções e práticas dos professores. In: MARTINS, Isabel P.; Paixão, F.; VIEIRA, Rui Marques. Perspectivas Ciência - Tecnologia -Sociedade na Inovação da Educação em Ciências. Universidade de Aveiro, p.47-55, 2004.

Vilches, Amparo. La introducción de las interacciones ciencia, técnica e sociedad (CTS). Una propuesta necesaria en la enseñanza de las ciencias. In Las Ciencias en la Escuela - Teorías y Prácticas. Barcelona: Editorial Graó, 2002.

Yager, R. E. STS: Thinking Over the Years. The Science Teacher, v.57, n.3, p.52-55, 1990.

Ana Lúcia Lopes Corrêa é doutoranda em Ensino de Ciências e Matemática pela Universidade Cruzeiro do Sul (UNICSUL) - São Paulo - SP. É professora de Física do Centro Federal de Educação Tecnológica de Minas Gerais (CEFETMG) - Belo Horizonte - MG analopescorrea@deii.cefetmg.br. Com apoio da CAPES.

Mauro Sérgio Teixeira de Araújo é doutor em Física pela Universidade de São Paulo - USP -SP. É professor do Programa de Pós-graduação em Ensino de Ciências e Matemática da Universidade Cruzeiro do Sul (UNICSUL) - São Paulo - SP. - mstaraujo@uol.com.br 